\section{PWE-126 \ר THE AFFECT OF BOLUS CONSISTENCY ON THE OESOPHAGEAL TRANSITION ZONE IN DYSPHAGIA PATIENTS}

doi:10.1136/gut.2011.239301.389

G Nutton, 1,* K Sparshott, 1 S A Riley ${ }^{2}$ Department of Gl Physiology, Sheffield Teaching Hospitals, Sheffield, UK; ${ }^{2}$ Department of Gastroenterology, Sheffield Teaching Hospitals, Sheffield, UK

Introduction Oesophageal manometry reveals a well-defined trough in peristaltic pressure amplitude in the upper oesophagus of healthy subjects. This manometric 'transition zone' (TZ) is associated with the striated-to-smooth oesophageal muscle fibre transition. The physiology of this region and its role in bolus transport in health and disease is incompletely understood.

Previous studies have suggested that transition zone abnormalities may account for only a small percentage of patients presenting with dysphagia. However these studies were performed using water swallows only, yet it is known that bolus consistency may have a marked effect on oesophageal contractions, especially in dysphagia patients. The aim of this study was therefore to study the effect of bolus consistency on TZ characteristics in healthy volunteers and patients with dysphagia.

Methods Following informed consent healthy volunteers and patients with endoscopy negative dysphagia underwent high resolution manometry (HRM) and multichannel intraluminal impedance (MII). Bread $(2 \times 2 \times 2 \mathrm{~cm})$ and water $(5 \mathrm{ml})$ boluses were given in random order. Following each swallow TZ length $(\mathrm{cm})$ and duration (s) was measured using the HRM contour maps and MII data were used to assess bolus clearance through the $\mathrm{TZ}$ region.

Results 10 healthy volunteers (age 20-35 years; four female, six male) and 8 dysphagia patients (age 33-64 years; three female, five male) were recruited. Eight of the healthy volunteers had normal manometric characteristics in terms of motility when swallowing water, 2 showed hypocontracting waveforms but were normal when swallowing bread. In healthy volunteers, bolus consistency had no significant effect on TZ length (water bolus $(\mathrm{WB})$ mean $=2.0 \mathrm{~cm}$, range $=0.6-$ $3.1 \mathrm{~cm}$, solid bolus $(\mathrm{SB})$ mean $=1.5 \mathrm{~cm}$, range $=0.0-3.9 \mathrm{~cm}$ ), however there was a significant difference for $\mathrm{TZ}$ duration $(\mathrm{WB}$ mean $=1.6 \mathrm{~s}, \mathrm{SB}$ mean $=1.1 \mathrm{~s}, \mathrm{p}=0.036$ paired $\mathrm{t}$ test $)$. In dysphagia patients, bolus consistency had a significant effect on TZ length $(\mathrm{WB}$ mean $=2.5 \mathrm{~cm}$, range $=0.4-5.2 \mathrm{~cm}, \mathrm{SB}$ mean $=1.2 \mathrm{~cm}$, range $=0.0-2.8 \mathrm{~cm}, \mathrm{p}=0.049$ paired $\mathrm{t}$ test $)$, but no significant difference in $T Z$ duration $(W B$ mean $=1.4 \mathrm{~s}$, $\mathrm{SB}$ mean $=1.1 \mathrm{~s})$. TZ length was longer in dysphagia patients when swallowing water compared to healthy volunteers (volunteers mean $=2 \mathrm{~cm}$, range $=0.6-3.1 \mathrm{~cm}$, patients mean $=2.5$ $\mathrm{cm}$, range $=0.4-5.2 \mathrm{~cm}$ ). Both patients and volunteers demonstrated incomplete bolus transit, in terms of the MII, at the TZ when swallowing a bread bolus.

Conclusion Bolus consistency has a significant effect on TZ characteristics in healthy volunteers and patients with dysphagia. The results suggest that previous studies, by studying the TZ characteristics of water boluses, may have underestimated the significance of TZ abnormalities as a cause of dysphagia.

\section{Competing interests None.}

Keywords bolus consistency, dysphagia, high resolution manometry, impedance, oesophagus, transition zone. 